Southern Illinois University Carbondale

OpenSIUC

Articles

Department of Criminology and Criminal Justice

Spring 4-11-2016

\title{
An Intersectional Approach to Race/Ethnicity, Sex, and Age Disparity in Federal Sentencing Outcomes: An Examination of Policy Across Time Periods
}

Jeffrey Nowacki

Southern Illinois University Carbondale, jnowacki@siu.edu

Follow this and additional works at: http://opensiuc.lib.siu.edu/ccj_articles

This Article is brought to you for free and open access by the Department of Criminology and Criminal Justice at OpenSIUC. It has been accepted for inclusion in Articles by an authorized administrator of OpenSIUC. For more information, please contact opensiuc@lib.siu.edu. 
An Intersectional Approach to Race/Ethnicity, Sex, and Age Disparity in Federal Sentencing Outcomes: An Examination of Policy across Time Periods

Key Words: Intersectionality, US Federal Sentencing, Disparity, Policy

Final Word Count: 9069

ABSTRACT: Approaches to intersectionality stress the importance of recognizing multiple, intersecting inequalities. As such, recent sentencing research has examined the changing role of extra-legal characteristics on United States federal sentencing outcomes in the aftermath of recent policy changes (e.g., United States v. Booker), but scholarship has less often examined these characteristics at the intersections of racelethnicity, gender, and, especially age. This article uses an intersectional approach to examine the influence of these characteristics net of legally-relevant characteristics. Using ordinary-least squares regression procedures, the author examines the role of the joint effects of extra-legal variables on sentence length decisions across four distinct time periods. Net of control variables, results indicate that young black men are the group most likely to receive the longest sentences, but interesting differences between other groups also emerge.

The focal concerns and causal attribution perspectives (Albonetti, 1991; Steffensmeier et al., 1998) suggest that judges in the United States (US) sentence criminal offenders based on three criteria: blameworthiness, protection to the community, and practical constraints and consequences. Judges rarely, however, have complete information regarding these criteria, so they must take steps to reduce uncertainty. They do this by using perceptual shorthands, which link these focal concerns to offender-level characteristics, such as race/ethnicity, gender, and age. These shorthands are often based on judges' own perceptions, stereotypes, and biases, but are also influenced by other considerations (Albonetti, 1991; Steffensmeier et al., 1993; Steffensmeier et al., 1998). 
While these perspectives present extra-legal considerations as though judges apply them in a straightforward way, each with its own independent contribution to the sentencing decision, in practice, judges' application of extra-legal variables is likely not straightforward. A number of studies have suggested that extra-legal variables are not independent (Doerner and Demuth, 2010; Steffensmeier et al., 1993, Steffensmeier et al., 1998). That is, it is not enough to simply look at race/ethnicity, gender, and age in isolation. Put simply, the level of identifiable disparity in sentencing outcomes may vary not just through race/ethnicity, gender, and age, but across the intersections of these characteristics. For example, sentencing disparity may look different depending on whether researchers examine white women, black women, Hispanic women, young Hispanic men, older white women, and so on (see Franklin, 2013; Franklin, 2015; Freiburger and Hilinski, 2013). While there is no shortage of research on disparity in US sentencing outcomes, the extent to which studies have examined the joint roles of extra-legal characteristics and policy is much narrower. I intend to fill this gap by incorporating an intersectional perspective (e.g., race/ethnicity, gender, and age) in the context of varying sentencing systems (mandatory and advisory guidelines) in the US.

The intersectional approach suggests that a complete understanding of inequalities requires a recognition of multiple, interlocking characteristics that contribute to an individual's social location (Collins, 2000, Crenshaw, 1989). Rooted in feminist theory, intersectionality prioritizes the race and gender dimensions of women of color (Crenshaw, 1991), but contemporary applications also apply to other groups. Moreover, intersectionality recognizes that "race, class, gender, sexuality, and other locations of inequality are dynamic, historically grounded, socially constructed power relationships that simultaneously operate at both the microstructural and macro-structural levels" (Burgess-Proctor, 2006:37). 
Extra-legal predictors of sentencing outcomes are also affected by sentencing structures. Prior to the 1980s, US district judges responsible for sentencing criminal offenders had relatively wide discretion available to them. They had relative freedom to decide whether offenders should be incarcerated, and for how long. In the 1980s, conservatives and liberals alike criticized the large amount of discretion available to judges (see Garland, 2001, Pratt, 2008), and in 1984, the US Sentencing Reform Act placed constraints on judicial discretion. In 1987, the US Federal Sentencing Guidelines altered sentencing so that judges were to only account for an offender's criminal history and the severity of the offense.

In the 2005 United States v. Booker case, the US Supreme Court ruled the mandatory nature of these US Federal Guidelines unconstitutional and in violation of the $6^{\text {th }}$ Amendment. This ruling, in effect, made the US Federal Guidelines advisory rather than mandatory. This decision serves as a research opportunity to examine judicial discretion, and more importantly, the effect of policy and practice on sentencing outcomes. Moreover, Booker provides an opportunity to compare the influences of extra-legal variables on sentencing outcomes, before and after the decision. Thus, Booker provides an opportunity for a "natural experiment" (Hofer, 2007).

The current study examines sentencing outcomes in the US based on the intersections of extra-legal variables (e.g., race/ethnicity, sex, and age) across time. In this study, I ask the following questions: do the joint effects of extra-legal variables influence sentencing outcomes? If so, does the influence vary across time period? Broadly, I argue that using an intersectional framework to examine sentencing disparity reveals differences across groups that are not visible using additive approaches. 
This research contributes to the literature on sentencing decisions and policy shifts by examining the non-independence of extra-legal variables, such as race/ethnicity, gender, and age. By modeling each of these characteristics independently, research is likely to present an incomplete understanding of the way that these factors operate in practice. In closely examining the intersections of these variables, the current research can test for variation across groups that is masked in research that focuses solely on main effects. While previous research has examined these intersections (see Doerner and Demuth, 2010; Steffensmeier et al. 1993; Steffensmeier et al. 1998), my research also integrates the role of US policy, and examines how the influence of these extra-legal characteristics may change over time. Sentencing and Race/Ethnicity, Sex, and Age: Independent Effects

One of the most widely-referenced theoretical perspectives in the sentencing literature is the focal concerns perspective (Steffensmeier et al., 1993; Steffensmeier et al., 1998). This perspective suggests that during sentencing, judges take three factors into consideration: the offender's blameworthiness, the offender's danger to the community, and practical constraints and consequences. While this perspective sounds parsimonious and straightforward, in practice, these processes are complicated. The perspective suggests that judges evaluate these three criteria and punish offenders based on those assessments, but judges rarely have access to complete information regarding blameworthiness, community protection, and practical constraints. Thus, they develop "perceptual shorthands" (Albonetti, 1991; Steffensmeier et al., 1998) to reduce some of this uncertainty. Often, these shorthands are linked to extra-legal characteristics, such as race/ethnicity, gender, and age.

As such, a large body of research has used this perspective to examine judicial discretion and sentencing decisions (Freiburger and Hilinski, 2011; Steffensmeier et al., 1993; 
Steffensmeier et al., 1998; Stemen et al., 2015). While much of the research finds that offense severity and criminal history are the most salient predictors of sentencing outcomes, extra-legal characteristics (e.g., perceptual shorthands) also influence sentencing decisions net of the legallyrelevant characteristics. Specifically, Steffensmeier and Demuth (2006) find that race/ethnicity and gender both exert effects on sentencing outcomes above and beyond legally relevant characteristics such that men and non-white offenders receive less favorable sentencing outcomes than other groups (see also Demuth and Steffensmeier, 2004; Warren et al., 2012). Moreover, Steffensmeier and Demuth (2006) find that Hispanic offenders are sentenced more harshly in both drug and non-drug offenses and conclude this for two reasons: 1) they lack the resources (e.g., adequate representation) to resist those sanctions, and 2) growing non-white populations create a sense of threat among dominant, majority groups, eliciting more stringent social controls (Blalock, 1967; Ulmer and Johnson, 2004). Steffensmeier et al. (1998) find that demographic characteristics, such as race, gender, and age affect sentencing outcomes both independently and jointly. Moreover, Johnson (2003) argues that mode of conviction (e.g., plea negotiations vs. going to trial) helps better understand uses of judicial discretion. Specifically, the author found evidence of extra-legal factors playing a larger role in trials than plea negotiations, most likely because offenders are punished for using courtroom resources (e.g., a strike against them in terms of practical constraints and consequences). Additionally, Kramer and Ulmer (2002) examine how focal concerns influence downward departures. Again, criminal history and offense severity exert the strongest influences over departure decisions, however, pleading guilty, gender, race, and courtroom context (e.g., size of the surrounding area) can also play a role. Each of these studies illustrates a link between courtroom decision-making and attempts to reduce uncertainty at the sentencing stage through perceptual shorthands. 
The Intersections of Race/Ethnicity, Sex, and Age

Recent developments in feminist criminology have stressed the importance of approaching questions of gender inequality from an intersectional framework that recognizes multiple, intersecting inequalities (see Bernard, 2013; Crenshaw, 1989; 1991; Burgess-Proctor, 2006; Collins, 2000). Broad analyses simply comparing men to women may assume that there is a single, universal womens' experience. That is, the oppression and marginalization experienced by women do not differ across other social characteristics. An intersectional approach rejects this premise and moves to the forefront the notion of social location and varying experiences for different groups of women. In particular, the social realities experienced by white women likely differ from those experienced by black and Hispanic women. Moreover, those realities experienced by young white women also differ from older white women, young Hispanic women, are other groups. Intersectionality highlights these distinctions.

While some intersectionality approaches reject the practice of placing women into categories, the intercategorical approach suggests that broad categories, such as race and gender, can be treated as "anchor points" (see Glenn, 2002; McCall, 2005). An intersectional approach can combine and expand these categories to reveal complexities that are not visible by simply examining race, gender, or other demographic characteristics in isolation. Thus, in some ways, an intersectional approach trades parsimony for complexity, but these complexities highlight important differences between women that are not understood using less complex methods. Thus, the intersectional approach reveals not only inequalities between men and women, but also between white and Hispanic women, black and Hispanic men, and so on. In short, intersectionality allows a greater understanding of the totality of social location (also see Baca Zinn \& Thornton Dill, 1996; Choo \& Ferree, 2010; Landry, 2007). 
One application for the intersectional approach is sentencing disparity. A large body of research suggests that female offenders often receive leniency at sentencing compared to men (see Bickel \& Peterson, 1991; Daly, 1989; 1994; Daly \& Bordt, 1995; Doerner \& Demuth, 2014; Spohn, 1999). The distinctions between women of different background characteristics (e.g., racial/ethnic and age groups) is less clear. Research has examined some of these joint characteristics (Doerner \& Demuth, 2010; Steffensmeier et al., 1998; Steffensmeier et al., 1993). This line of research reveals inequalities in social responses to offending that are not clear by simply examining differences between men and women more broadly.

A number of studies within the sentencing literature have examined sentencing outcomes at these intersections (Brennan, 2009; Maggard et al., 2013; Steffensmeier et al., 1993; Steffensmeier et al., 1998). For example, research indicates that black women are sentenced about as harshly as white men (Spohn, 1985; Steffensmeier and Demuth, 2006). Perhaps the most prominent study of sentencing disparity that takes sex and other key status dimensions into account is Steffensmeier et al.'s (1998) work that examined sex, race, and age of offenders. In general, they found that young, black men are sentenced more harshly than any other group, but they also found differential sentencing of women across race and ethnicity, such that black women were sentenced more harshly than white women.

Other research also finds differential sex effects across race and ethnicity. Race and ethnicity have been linked to enhanced sentences for women offenders (Crawford, 2000) in terms of incarceration decisions and sentence length (Crew, 1991; Crow and Kunselman, 2009; Spohn, 1999; 2013), pre-trial release (Demuth and Steffensmeier, 2004), adjudication (Freiburger and Burke, 2011), and dispositions (Horowitz and Pottieger, 1991, Moore and Padavic, 2010). Moreover, black women are more likely than white women to receive further 
court processing at intake (Leiber and Mack, 2003), and black and Hispanic women are more likely than white women to receive jail sentences (Brennan, 2006). Finally, women offenders who fall into the lower socio-economic status are more likely to receive severe sanctions (Brennan, 2006; Kruttschnitt, 1981). Clearly, researchers should account for the intersections of multiple status dimensions in order to fully understand the complexities of social location and sentencing.

\section{US Federal Sentencing Guidelines}

US federal sentencing decisions followed the US Federal Sentencing Guidelines through the 1990s and into the year 2000. Over the course of this time, the US Federal Guidelines underwent a number of changes and absorbed the effects of smaller policy changes. Chiefly among them was the PROTECT Act of 2003. The Feeney Amendment of the PROTECT Act essentially reduced opportunities to mitigate sentencing outcomes through downward departures (see Friddle and Sands, 2004; Ulmer et al., 2011b). Policy changes such as this highlight the importance of examining broad policy structures, such as the US Federal Guidelines, over time. In the years that followed the Feeney Amendment and the PROTECT Act, the US Federal Guidelines system became the target of several challenges (Apprendi v. New Jersey, 2000; Washington v. Blakely, 2004). In January 2005, the United States v. Booker decision shifted the US Guidelines from mandatory to advisory, after the US Supreme Court ruled their mandatory nature in violation of the $6^{\text {th }}$ Amendment (see Hofer, 2007; Kramer, 2009; Nowacki, 2015). ${ }^{1}$ This change was substantial, with significant implications for sentencing practices. Under the post-Booker system, judges were to use the guidelines as a starting point from which they could depart, and in some cases, use extra-legal characteristics to guide sentencing decisions. 
While Booker afforded judges more freedom to depart from unreasonable sentences, it was not always clear what was unreasonable. This was specified more clearly in 2007 in the Gall v. United States and Kimbrough v. United States cases. In Gall, the US Supreme Court ruled that judges should not assume that the guidelines recommendations are reasonable, and they should reach their own assessments based on the facts of the case. Moreover, in Kimbrough, the US Supreme Court ruled that judges could expect that US Guidelines sentences were not reasonable in cases involving crack cocaine (see Ulmer et al., 2011b).

The effects of Booker and Gall have been subject to empirical testing since the US Guidelines were made advisory. This body of research suggests that since Booker, the volume of departures has increased (Hofer, 2007), but in a broad sense, racial disparity in US sentencing has not increased (Fischman and Schanzenbach, 2012; Lynch and Omari, 2014; Starr and Rehavi, 2013; Ulmer et al., 2011a; 2011b). The current research pays greater attention to differences at the intersections of race/ethnicity, sex, and age to examine whether some groups have been affected differently than others.

Data \& Methods

The present research draws on data from the Monitoring of Federal Criminal Sentences database from 1999-2008, which are available through the Inter-University Consortium for Political and Social Research (ICPSR). These data are compiled by the United States Sentencing Commission (USSC) and include all convicted federal offenders from each of the 94 US districts, making this dataset the most comprehensive available for federal offenses and offenders. ${ }^{2}$ These data include information on the sentence length, type of offense, legal variables, such as criminal history and severity of the offense, and extra-legal variables, such as race/ethnicity, age, gender, location (district), education, and a variety of others. 


\section{Dependent Variable}

The dependent variable in this study is sentence length (in months, capped at 470). ${ }^{3}$ The Monitoring of Federal Criminal Sentences database provides a final sentence length for each offender. Following previous research, I exclude zero month prison sentences (see Ulmer et al., 2011b). Even when these sentences are excluded, the data is highly skewed. To address this, I take the natural log of sentence length (see Steffensmeier et al., 1993; Steffensmeier et al., 1998), which adjusts for the non-normal distribution of the data. Finally, following previous research, immigration offenses are also excluded from the analyses (see Ulmer et al., 2011a; 2011b). Independent Variables

The key independent variable in this study is the joint effect of race/ethnicity, sex, and age. First, dummy variables are constructed for black and Hispanic offenders, with white offenders serving as the reference category. Next, a dummy variable is constructed for sex where women offenders are coded as " 1 " and otherwise " 0 ." Finally, dummy variables for age are constructed for young offenders (those 30 years of age or younger) and older offenders (those at least 50 years of age), with the middle group (ages 31-49) serving as the reference category. Finally, intersectional categories are created by combining the race/ethnicity, sex, and age dummy variables. For example, an offender is coded as a young, white, man if that offender is 30 or younger, male, and white. The reference category for this set of joint effect variables is white men aged 31-49. Treating this group as the reference category most clearly illustrates potential disparities among non-white, women, and younger or older offenders. Legal Variables

With respect to legally-relevant variables, I include measures that capture the magnitude of the offender's criminal history, the presumptive sentence, whether the offense was a violent 
offense, whether the offense was a drug offense, whether the offense went to trial, and whether the offender was held in custody prior to trial. Criminal history is measured on a continuum from 1-6, with scores of 1 representing the least extensive criminal histories, and those with 6 representing the most extensive. The presumptive sentence is the Guidelines minimum sentence for offender's offense severity-criminal history combination. This allows a control for offense severity. For the violent offense variable, violent offenses are coded as " 1 ," while other offenses are coded as 0 . For the drug offense variable, drug offenses are coded as " 1 ," while other offenses are coded as " 0 ." Finally, for the trial variable, cases that went to trial were coded as " 1 " and otherwise " $0 . "$

Control Variables

In addition to these measures, I also control for a number of other variables. These include level of education, US citizenship status, and whether the defendant was detained prior to the trial. Education is dummy coded such that those with at least a high school degree are coded as " 1 " and otherwise " 0 ." Citizenship status is a dummy variable indicating whether the offender is a US citizen (coded as " 1 "). Detainment status is dummy-coded and scored as " 1 " if the offender is held prior to trial. In all models, I include controls for sentencing year (where appropriate) by including a set of dummy variables (not shown in tables). This accounts for nonindependence across sentencing year.

Analytic Strategy

Following both the United States Sentencing Commission Report (2010) and recent research on US federal sentencing outcomes (Ulmer et al. 2011a, 2011b), the data is partitioned into four time periods: the pre-PROTECT period (1999-April 2003), the post-PROTECT period 
(May 2003- December 2004), the post-Booker period (January 2005-November 2007), and the post-Gall period (December 2007-2008).

The dependent variable is estimated using ordinary least squares regression techniques. In each time period, I control for other case-level variables (described above), and include fixedeffects for sentencing district. The primary focus, however, is to examine the joint effects of race/ethnicity, sex, and age together, which, again, speaks to the intersectional nature of these extra-legal characteristics, and potentially reveals masked variation across groups. ${ }^{4}$

Comparisons of categorical variables, such as the ones used in this article, are generally done by assigning one category as the "reference category", and excluding that category from the regression model. Each other category is then interpreted in relation to that reference category. Making comparisons against the reference category is straightforward, but making comparisons between the other categories introduces additional complexity. A solution to this problem with reference categories is to report quasi-variances along with each category, including the reference (see Firth, 2000; 2003; Gayle \& Lambert, 2007). These quasi-variances can then be used to conduct accurate statistical tests to assess differences between the non-reference categories. ${ }^{5}$ I report quasi-variances for each category in each time period. These quasivariances were calculated using Firth's online calculator (Firth, 1998).

Results

Results from regression models are presented in Tables 2-5. I begin with results from the Pre-PROTECT period (Table 2). According to the OLS model, belonging to the young, black, male group increases sentence length more than membership to any other group $(b=.082)$. As noted earlier, however, this interpretation suffers from the reference category problem. That is, this model tells us that young, black men receive the most punitive sentences relative to the 
reference category (e.g., white men aged 31-49), but does allow a comparison against other groups. In order to accomplish this, I use quasi-variances to calculate t-statistics which help determine whether the differences between groups are statistically significant.

Using quasi-variances reported in Table 2, I make direct comparisons across groups. I begin by testing for racial/ethnic differences between young men. When comparing young black men to young Hispanic men, results indicate that membership in the young black male group produce more punitive sanctions than membership in the young Hispanic male group $(\mathrm{t}=$ 14.757). Conversely, results show that compared to young white men, the young Hispanic male status produces longer sentences $(\mathrm{t}=6.7)$. Finally, young black men also receive more punitive sentences compared to young white men $(\mathrm{t}=7.695)$. In short, at least as far as young men are concerned, black offenders tend to receive the most punitive sentences.

The next comparison illustrates the age effect among men within the same racial/ethnic group. These results indicate that net of other factors, young black men receive more punitive sentences than black men aged 31-49 $(\mathrm{t}=10.857)$ or older black men $(\mathrm{t}=10.35)$. For Hispanic offenders, young Hispanic men receive more lenient sentences than Hispanics aged 31-49 $(\mathrm{t}=$ 3.3) and there is no statistically significant difference between young Hispanic men and older Hispanic male offenders $(\mathrm{t}=1.196)$. Finally, for whites, results from the pre-PROTECT period show that young white men receive more lenient sentences than either white men aged $31-49(\mathrm{t}=$ $-6.485)$ or older white offenders $(t=-2.193)$. While younger black offenders receive more punitive sanctions than black offenders in other age groups, younger offenders in the Hispanic and white groups receive the more lenient sentences.

The final comparison from the pre-PROTECT period highlights differences among women offenders. While all young female offenders receive lenient sentences relative to men, 
young white women receive the most lenient sentences, compared to young black women $(\mathrm{t}=$ 2.108) and young Hispanic women $(\mathrm{t}=9.051)$. Results also indicate that young black women receive more lenient sentences than young Hispanic women $(t=-7.33)$. Compared to other black female offenders, young black women receive more lenient sentences than black women aged 31-49 $(\mathrm{t}=-4.164)$, but there is no statistically significant difference between young black women and older black women $(\mathrm{t}=-1.478)$. Moreover, young Hispanic women receive more lenient sentences than women aged $31-49(t=-5.745)$, but there is no statistically significant difference between younger and older women $(t=-.936)$. Finally, among white women, younger white women tend to receive more lenient sentences than either white women aged 31-49 $(t=-8.803)$ or older white women $(t=-6.857)$. For women, there appears to be few differences between the sentences meted out to the youngest and oldest offenders, but for white women, the youngest offenders receive the largest sentencing discount.

Post-PROTECT Era

Results from the post-PROTECT period are presented in Table 3. Similar to the prePROTECT period, the OLS model suggests that membership in the young, black male category produces more punitive sentences than membership to any other group in the data $(b=.054)$. To address the reference category problem, I use quasi-variances to examine differences across several groups. These comparisons indicate that young black men receive more punitive sanctions compared to young white men $(t=7.155)$ and young Hispanic men $(t=5.14)$. However, the difference between young white men and young Hispanic men does not reveal a statistically significant difference $(\mathrm{t}=1.909)$. Thus, at least as far as young men are concerned, young black men appear to receive the most punitive responses. 
Next, I compare the influence of age between men within the same racial category. Using quasi-variances to calculate t-scores, I find that young black men receive more punitive sentences than either black men aged 31-49 $(t=10.646)$ or older black men $(t=5.165)$. Turning to Hispanic offenders, young Hispanic men actually receive more lenient sentences than Hispanic males aged 31-49 $(\mathrm{t}=-2.562)$, however no statistically significant difference emerges between young and older Hispanic men $(t=-.322)$.

Finally, I examine differences between women in the post-PROTECT period. In contrast to young black men, young black women actually receive the most lenient sentences compared to young white women $(t=-3.391)$ or young Hispanic women $(t=-7.503)$. Moreover, results indicate that young white women receive more lenient sentences than young Hispanic women ( $t$ =4.402). Thus, out of the young women, Hispanic women seem to receive the smallest benefit. Comparing age effects within women from the same racial/ethnic groups shows that young black women receive more of a chivalry benefit than either black women aged 31-49 $(t=-5.514)$ or older black women $(\mathrm{t}=-2.182)$. Likewise, young Hispanic women receive more lenient sentences than either Hispanic women aged 31-49 $(t=-4.677)$ or older Hispanic women $(t=-$ 3.988). Similarly, among white women, young white women receive the most lenient sanctions compared to white women aged 31-49 $(t=-4.382)$ or older white women $(t=-2.914)$. Thus, for each racial/ethnic group, the youngest group of women receive the largest sentencing discount.

\section{POST-BOOKER Era}

Results from the post-Booker period appear in Table 4. As in both pre-Booker periods, the effect of being young, black, and male produces the strongest effect on sentence length $(b=$ .097) in the OLS model. Examination of quasi-variances supports this result, as young black men are sentenced more punitively than either young white men $(t=11.632)$ or young Hispanic 
men $(t=8.677)$. A comparison between young Hispanic and young white men shows that young Hispanic men receive more punitive sentences $(t=2.830)$. Thus, it appears that of the young offenders, black men receive the most stringent penalties followed by Hispanic men.

Investigation of age differences within racial/ethnic categories among men suggests that young, black men receive more punitive sentences than either black men aged 31-49 $(\mathrm{t}=10.4)$ or older black men $(t=9.1)$. Conversely, young Hispanic men actually receive more lenient sentences than Hispanic men aged 31-49 ( $\mathrm{t}=-7.029)$, but no statistically significant difference emerges between young and older Hispanic men $(\mathrm{t}=-1.464)$. Finally, and in contrast to black men, young white men received more lenient sentences than either white men aged 31-49 $(\mathrm{t}=$ $2.5)$ or older white men $(\mathrm{t}=-3.162)$. In short, for black offenders, young men receive the harshest sentences, for Hispanic offenders, the offenders aged 31-49 receive the most punitive sanctions, and for white offenders, the oldest group of offenders receive the longest sentences.

Now I turn to sentences for women offenders during the post-Booker period. Similar to the pre-Booker periods, young black women tend to receive sentences shorter than either young white women $(\mathrm{t}=-.2170)$ or young Hispanic women $(\mathrm{t}=-6.493)$. A comparison between young white and young Hispanic women offenders also shows that young white women receive the shorter sentences, which also mirrors results from the pre-Booker periods. Comparing age effects shows that young black women receive shorter sentences than either black women aged 31-49 $(\mathrm{t}=-5.063)$ or older black women $(\mathrm{t}=-2.259)$. Similarly, young Hispanic women receive more lenient sanctions than either Hispanic women aged 31-49 $(\mathrm{t}=5.367)$ or older Hispanic women $(t=-3.955)$. Finally, young white female offenders receive more lenient sentences than either white women aged 31-49 $(\mathrm{t}=-3.298)$ or older white female offenders $(\mathrm{t}=-4.133)$. These 
results indicate that irrespective of racial/ethnic group, the youngest offenders receive the largest sentencing discount.

Post-Gall Period

The last set of results are presented in Table 5. As with each of the preceding models, the OLS results indicate that young black men receive the most punitive sentences $(b=.163)$. The quasi-variance approach confirms this result, as young black men receive more punitive sentences than either young white men $(t=9.145)$ or young Hispanic men $(t=5.303)$. Moreover, young Hispanic men receive more punitive sentences than young white men $(\mathrm{t}=$ 3.450). For young offenders, black men receive the harshest sentences, followed by Hispanic men, followed by white men.

Next, I examine age differences with racial/ethnic groups for men in the post-Gall period. Similar to the previous periods, young black men receive more lenient sentences than either black men aged 31-49 $(\mathrm{t}=5.396)$ or older black men $(\mathrm{t}=5.593)$. Turning to Hispanic offenders, young Hispanic men receive more lenient sentences than Hispanic men aged 31-49 $(\mathrm{t}=-3.264)$, but there is no statistically significant difference between young and older Hispanic men $(\mathrm{t}=$ $.550)$. In the case of white men, there is no statistically significant difference between young white men and either white men aged 31-49 $(\mathrm{t}=-.695)$ or older white men $(\mathrm{t}=-1.647)$. Thus, sentencing outcomes appear to be independent of age for white men.

Finally, I examine women in the post-Gall period. Unlike in the previous time periods, there is no statistically significant difference in the sentences meted out to young black women and young white women $(\mathrm{t}=.766)$. Compared to young Hispanic women, however, young black women receive more lenient sentences in this period $(t=-2.4)$. Moreover, young white women also receive more lenient sentences than young Hispanic women $(t=3.416)$. Thus, it seems that 
out of the young female offenders, Hispanic women are treated most harshly during the postGall period. The final comparisons examine the age effect among women within racial/ethnic categories. Beginning with black women, results indicate that there is no statistically significant difference in sentencing outcomes for young black women and black women aged 31-49 $(\mathrm{t}=-$ $.310)$ and older black women $(t=-.976)$. Turning to Hispanic women, results suggest that young Hispanic women are sentenced more harshly than Hispanic women aged 31-49 $(\mathrm{t}=-2.008)$, but there is no difference between young and older Hispanic women $(\mathrm{t}=-1.626)$. Finally, among white women, there is no statistically significant difference between young white women and white women aged 31-49 $(\mathrm{t}=-1.382)$ or young white women and older white women $(\mathrm{t}=-.640)$. Thus, in the post-Gall era, sentencing outcomes are independent of age for white and black women, but not Hispanic women.

Discussion

A number of studies in the sentencing literature have examined disparities across race/ethnicity, sex, and age (Spohn, 1999; Spohn et al., 1981; Steffensmeier et al., 1995). Some studies have also examined the joint nature of these categories at both the state (Steffensmeier et al., 1998; Steffensmeier et al., 1993) and federal levels (Doerner \& Demuth, 2010) in the US. This study expands on this line of research by also accounting for changes over time, as policies ebb and flow at the federal level. Broadly, results suggest that comparisons across race/ethnicity-sex-age combinations remain relatively stable across time period and policy implementation, but some noteworthy findings do emerge. In particular, this research approaches this issue from an intersectional lens, highlighting the role of social location in criminal justice responses to offending. 
First and foremost, the results from these analyses suggest that young black men are sentenced more punitively than any other group during each time period. Steffensmeier et al. (1998:769) suggested that young black men represent a "dangerous class" and are prone to criminal activity. This finding cannot be explained completely by propensity to engage in criminal behavior, because this effect operates net of legally-relevant variables, such as criminal history and offense severity. It is likely that young, black men are disadvantaged at the sentencing stage as a function of social location.

What may be less clear is the notion that these supposed "legally-relevant variables" are linked to and influenced by extra-legal characteristics, such as those examined here: race/ethnicity, sex, and age. It is quite likely that young black men are more likely to be contacted by police (Kempf-Leonard, 2007), more likely to be arrested (Ousey \& Lee, 2008), and more likely to be convicted of offenses than other race/ethnicity-sex-age combinations. Thus, these legally-relevant considerations generate a perception that young black men are the most dangerous class (see Steffensmeier et al., 1998). In the end, it is not possible to completely disentangle criminal history and offense severity from extra-legal characteristics, because the two are mutually reinforcing. That is, because young black men elicit more punitive responses at all stages of the US criminal justice system, members of this class develop more extensive criminal records. As young black men generate these more extensive criminal records, the perception that they are more dangerous than other classes is reinforced. If these disparities are simply a function of differential treatment in the US criminal justice system, then those responses can be rectified through training and assessment. If instead the disparities are a function of differential criminal behavior, it is important that we can identify what about social location makes them more prone to crime, and address those issues at the core. 
Another interesting finding is that out of the young women, young Hispanic women received the harshest sentences. It is perhaps expected that young Hispanic women would be sentenced more harshly than young white women, but the result that they are sentenced more harshly than young black women is unexpected. It is perhaps explainable, however, by some of the obstacles that young, Hispanic women may face, such as language barriers and lack of social networks (see Pasko, 2002). Moreover, young Latinas may be less likely to cooperate with prosecutors by accepting responsibility or providing information that could lead to the conviction of other offenders (Pasko, 2002).

This study also made use of quasi-variances to make comparisons across race/ethnicitysex-age categories. This technique corrects for the reference category problem where comparisons against a single reference category do not allow accurate comparisons across other groups. The results in this paper show that simply using the coefficient between a category and the reference can provide different results than the quasi-variance technique. For example, in all of the pre-Gall periods, the young Hispanic male category was not significantly different from the reference category (e.g., white men aged 31-49). However, when young Hispanic men were compared to young white men, statistically significant differences were found in each period except for the post-PROTECT period. Moreover, differences were found in comparison to young black men in each period. Thus, failure to use the quasi-variance method of comparison would produce inaccurate results and mask potential differences between groups.

This study was not without limitations. As is often an issue with archival data, the analysis was limited to variables available in the USSC database. One interesting set of variables is judicial characteristics, such as race/ethnicity, sex, age, tenure, and prosecutorial experience of judges. Research indicates that sentencing practices may vary across these characteristics 
(Steffensmeier and Herbert, 1999; Welch et al., 1988). Moreover, I do not have measures of prosecutorial discretion, which also have important implications for sentencing outcomes linked to the prosecutor's role in the plea bargaining process and initiating departures and other mitigating factors in US sentencing (Engen and Steen, 2000; Miethe, 1987).

The PROTECT Act, and Booker and Gall decisions only affected one type of policy: mandatory US Federal Sentencing Guidelines. Some scholars suggest that even though the latter court decisions made the Guidelines less binding (Lynch and Omari, 2014), other policies such as mandatory minimums may still produce disparities in sentencing (Fischman and Schanzenbach, 2012). Future research should continue to examine sentencing policy, including mandatory minimums, as the policy implications for disparity in sentencing may more closely entail changes to those types of policies rather than guidelines.

Finally, the present research only looks directly at sentencing outcomes, and does not address non-custodial sanctions. The processes and nature of discretion could vary substantially for these types of sentences. After all, it seems reasonable that discretion could play the greatest role for sanctions at the low-end of the sentencing distribution. Future research should examine not only custodial but also non-custodial sanctions.

In conclusion, this research examines the influence of the United States v. Booker decision (and other policy) on US sentencing outcomes. The preceding analyses illustrate the notion of extra-legal variables exerting considerable influences over sentencing outcomes net of legally relevant characteristics such as criminal history and offense severity in nuanced ways. Specifically, I demonstrate the importance of examining race/ethnicity, sex, and age as joint effects. Overall, it seems clear that judicial discretion (and moreover, discretion at large) plays a role in sentencing decisions, and that role varies across social location. 
Notes

1. The development, implementation, and evolution of the US Federal Sentencing Guidelines has been thoroughly documented elsewhere. In particular, see Stith and Cabranes, 1998; Frase, 2007; and Johnson, Ulmer, and Kramer, 2008.

2. I include 89 of the 94 districts in my analyses. I exclude districts from Puerto Rico, Guam, and other US territories.

3. Many studies of sentencing which model sentence length as a dependent variable include a correction term for selection bias, which is linked to the decision to incarcerate. In the case of US federal data, the majority of offenders are incarcerated (approximately 90\%). Given this low level of selection, the selection bias term is omitted in this study (see Doerner and Demuth, 2014; Franklin, 2015).

4. While examining main effects and race/ethnicity-sex combinations could provide an interesting exercise in intuition-building, anonymous reviewers have pointed that those hypotheses have been sufficiently tested in previous research using similar data (see Ulmer et al., 2011a; USSC, 2010). Thus, I present only the joint models here.

5. T-statistics are calculated using the following formula: $\mathrm{t}=\frac{b 1-b 2}{\sqrt{\text { quasi var }(b 1)+q u a s i \text { var }(b 2)}}$. Tstatistics greater than 1.96 or less than -1.96 indicate statistically significant differences between groups. 


\section{References}

Albonetti CA (1991) An integration of theories to explain judicial discretion. Social Problems 38: 247-266.

Apprendi v. New Jersey (2000) Supreme Court of the United States. 530 U. S. 466.

Baca Zinn M. and Thornton Dill B. (1996) Theorizing difference from multiracial feminism. Feminist Studies 22(2): 321-331.

Bernard A (2013) The intersectional alternative: Explaining female criminality. Feminist Criminology 8: 3-19.

Bickle GS and Peterson, RD (1991) The impact of gender-based family roles on criminal sentencing. Social Problems 1: 372-394.

Blalock HM (1967) Toward a theory of minority-group relations. New York: John Wiley and Sons.

Brennan PK (2009) Race and sentencing outcomes among female drug offenders in North Carolina: An exploratory consideration of earlier case processing outcomes. Journal of Crime and Justice 32: 77-115.

Brennan PK (2006) Sentencing female misdemeanants: An examination of the direct and indirect effects of race/ethnicity. Justice Quarterly 23: 60-95.

Burgess-Proctor A (2006). Intersections of race, class, gender, and crime future directions for feminist criminology. Feminist Criminology 1: 27-47.

Choo HY and Ferree MM (2010) Practicing Intersectionality in Sociological Research: A Critical Analysis of Inclusions, Interactions, and Institutions in the Study of Inequalities. Sociological Theory 28(2): 129-149.

Collins Hill P (2000). Black feminist thought-Knowledge, consciousness, and the politics of empowerment. London: Routledge.

Crawford C (2000) Gender, race, and habitual offender sentencing in Florida. Criminology 38: 263-280.

Crenshaw K (1991) Mapping the margins: Intersectionality, identity politics, and violence against women of color. Stanford Law Review 43: 1241-1299.

Crenshaw K (1989). Demarginalizing the intersection of race and sex: A black feminist critique of antidiscrimination doctrine, feminist theory and antiracist politics. University of Chicago. Legal Forum 19: 139-168.

Crew BK (1991) Sex differences in criminal sentences: Chivalry or patriarchy? 
Justice Quarterly 8: 59-83.

Crow MS and Kunselman JC (2009) Sentencing female drug offenders:

Reexamining racial and ethnic disparities. Women and Criminal Justice 19: 191-216.

Daly K (1989) Rethinking judicial paternalism: Gender, work-family relations, and sentencing. Gender \& Society 3: 9-36.

Daly K and Bordt RL (1995) Sex effects and sentencing: An analysis of the statistical literature. Justice Quarterly 12(1): 141-175.

Demuth S and Steffensmeier D (2004) The impact of gender and race-ethnicity in the pretrial release process. Social Problems 51: 222-242.

Doerner JK and Demuth S (2014) Gender and sentencing in the federal courts: Are women treated more leniently? Criminal Justice Policy Review 25(2): 242-269.

Doerner, JK. and Demuth S (2010). The independent and joint effects of race/ethnicity, gender, and age on sentencing outcomes in U.S. Federal courts. Justice Quarterly 27: 127.

Engen RL and Steen S (2000) The power to punish: Discretion and sentencing reform in the War on Drugs. American Journal of Sociology 105: 1357-1395.

Firth D (2003) Overcoming the reference category problem in the presentation of statistical models. Sociological Methodology 33(1): 1-18.

Firth D (2000) Quasi-variances in Xlisp-Stat and on the web. Journal of Statistical Software 5: i04.

Firth D. (1998) The QV Calculator. At http://www.stats.ox.ac.uk/ firth/qvcal

Fischman JB and Schanzenbach MM (2012) Racial disparities under the federal sentencing guidelines: The role of judicial discretion and mandatory minimums. Journal of Empirical Legal Studies 9: 729-764.

Franklin TW (2015) Race and ethnicity effects in Federal sentencing: A propensity score analysis. Justice Quarterly 32: 653-679.

Franklin TW (2013) Sentencing Native Americans in U.S. federal courts: An examination of disparity. Justice Quarterly 30: 310-339.

Frase RS (2007) The Apprendi-Blakely cases: Sentencing reform counter revolution? Criminology \& Public Policy, 6(3), 403-431.

Freiburger TL and Burke AS (2011) Status offenders in the juvenile court: The 
effects of gender, race, and ethnicity on the adjudication decision. Youth Violence \& Juvenile Justice 9: 352-365.

Freiburger TL and Hilinski CM (2013) An examination of the interactions of race and gender on sentencing decisions using a trichotomous dependent variable. Crime \& Delinquency 59: 59-86.

Friddle T and Sands JM (2004) Don't think twice, it's all right: Remands, Federal Sentencing guidelines \& (and) the PROTECT Act-A radical departure. Arizona State Law Journal, 36, 527-550.

Gall v. United States (2007) Supreme Court of the United States 552 U.S. 38.

Garland D (2001) The culture of control: Crime and social order in contemporary society. Oxford University Press.

Gayle V and Lambert PS (2007). Using quasi-variance to communicate sociological results from statistical models. Sociology 41(6): 1191-1208

Glenn EN (2002) Unequal freedom: How race and gender shaped American freedom and labor. Cambridge, MA: Harvard University.

Hofer PJ (2007) United States v. Booker as a natural experiment: Using empirical research to inform the federal sentencing policy debate. Criminology and Public Policy, 6: 433-460.

Horowitz R and Pottiger AE (1991) Gender bias in juvenile justice handling of serious crime-involved youth. Journal of Research in Crime and Delinquency 28: 75-100.

Johnson BD (2003) Racial and ethnic disparities in sentencing departures across modes of conviction. Criminology 41: 449-489.

Johnson BD, Ulmer JT, and Kramer JH (2008) The social context of guidelines circumvention: The case of federal district courts. Criminology 46: 737-783.

Kempf-Leonard K (2007) Minority youths and juvenile justice disproportionate minority contact after nearly 20 years of reform efforts. Youth Violence and Juvenile Justice 5(1): 71-87.

Kimbrough v. United States (2007) Supreme Court of the United States. 552 U. S. 85.

Kramer JH (2009) Mandatory sentencing guidelines: The framing of justice. Criminology \& Public Policy 8: 313-321.

Kramer JH and Ulmer JT (2002) Downward departures for serious violent offenders: Local court 'corrections' to Pennsylvania's sentencing guidelines. Criminology 40: 897-932. 
Kruttschnitt C (1981) Social status and sentences of female offenders. Law \& Society Review 15: 247-265.

Landry B (2007) Race, gender, and class: Theory and methods of analysis. New Jersey: Pearson.

Leiber MJ and Mack KY (2003) The individual and joint effects of race, gender, and family status on juvenile justice decision-making. Journal of Research in Crime and Delinquency 40: 34-70.

Lynch M and Omori M (2014) Legal change and sentencing norms in the wake of Booker: The impact of time and place on drug trafficking cases in federal court. Law \& Society Review 48: 411-445.

Maggard SR, Higgins JL, and Chappell AT (2013) Pre-dispositional juvenile detention: An analysis of race, gender, and intersectionality. Journal of Crime and Justice 36: 6786.

McCall L (2005) The complexity of intersectionality. Signs 30: 1771-1800.

Miethe TD (1987) Charging and plea bargaining practices under determinate sentencing: An investigation of the hydraulic displacement of discretion. Journal of Criminal Law and Criminology 155-176.

Moore LD and Padavic I (2010) Racial and ethnic disparities in girls' sentencing in the juvenile justice system. Feminist Criminology 5: 263-285.

Nowacki JS (2015) Race, ethnicity, and judicial discretion: The influence of the United States v. Booker Decision. Crime \& Delinquency 61: 1360-1385.

Ousey, GC and Lee MR (2008) Racial disparity in formal social control: An investigation of alternative explanations of arrest rate inequality. Journal of Research in Crime and Delinquency 45(3): 322-355.

Pasko L (2002) Villain or victim: Regional variation and ethnic disparity in Federal drug offense sentencing. Criminal Justice Policy Review 13: 307-328.

Pratt T (2008) Addicted to incarceration: Corrections policy and the politics of misinformation in the United States. Sage Publications.

Spohn C (2013) Effects of the offender's race, ethnicity, and sex on federal sentencing outcomes in the guidelines era. Law \& Contemporary Problems 76: 75-104.

Spohn C (1999) Gender and sentencing of drug offenders: Is chivalry dead? Criminal Justice Policy Review 9: 365-399. 
Spohn C (1985) Women defendants in court: The interaction between sex and race in convicting and sentencing. Social Science Quarterly 66: 178-185.

Spohn C, Gruhl J, and Welch S (1981) The effect of race on sentencing: A re-examination of an unsettled question. Law and Society Review: 71-88.

Starr SB and Rehavi MM (2013) Mandatory sentencing and racial disparity: Assessing the role of prosecutors and the effects of Booker. Yale Law Journal 129: 2-80.

Steffensmeier D and Demuth S (2006) Does gender modify the effects of raceethnicity on criminal sanctions? Sentences for male and female, White, Black, and Hispanic defendants. Journal of Quantitative Criminology 22: 241-261.

Steffensmeier D and Herbert C (1999) Women and men policymakers: Does the judge's gender affect the sentencing of criminal defendants? Social Forces 77: 1163-1196.

Steffensmeier D, Kramer J, and Streifel C (1993) Gender and imprisonment decisions. Criminology 31: 411-446.

Steffensmeier D, Kramer J, and Ulmer J (1995) Age differences in sentencing. Justice Quarterly 12(3): 583-602.

Steffensmeier D, Ulmer J and Kramer J (1998) The interaction of race, gender, and age in criminal sentencing: The punishment cost of being young, black, and male. Criminology 36: 763-797.

Stemen D, Rengifo AF, and Amidon E (2015) The focal concerns of sentencing and mandatory sentencing laws: circumvention in the context of mandatory probation and treatment. Journal of Crime and Justice 38: 183-203.

Stith K and Cabranes JA. (1998) Fear of judging: Sentencing guidelines in the federal courts. IL: University of Chicago Press.

Tonry M (1996) Sentencing matters. New York: Oxford University Press.

Ulmer JT and Johnson B (2004) Sentencing in context: A multilevel analysis. Criminology 42: 137-177.

Ulmer J, Light MT, and Kramer J (2011a) The 'liberation' of federal judges' discretion in the wake of the Booker/Fanfan decision: Is there increased disparity and divergence between courts? Justice Quarterly 28: 799-837.

Ulmer J, Light MT, and Kramer J (2011b) Racial disparity in the wake of the Booker/Fanfan decision. Criminology \& Public Policy 10: 1077-1118.

United States v. Booker (2005) Supreme Court of the United States 543 U.S. 220. 
Warren P, Chiricos T, and Bales W (2012) The imprisonment penalty for young black and Hispanic Males: A crime-specific analysis. Journal of Research in Crime and Delinquency 49: 56-80.

Washington v. Blakely (2004) Supreme Court of the United States 542 U.S. 296.

Welch S, Combs M, and Gruhl J (1988) Do black judges make a difference? American Journal of Political Science 32: 126-136. 
Table 1. Descriptive Statistics (Mean Value with Standard Deviation in Parentheses)

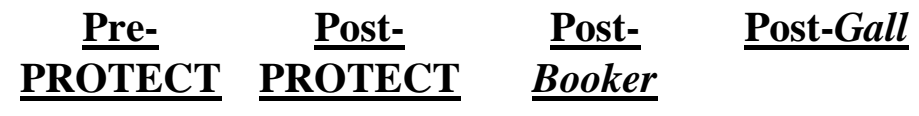

\section{Dependent Variable}

Sentence Length

Independent Variables

Black

Hispanic

Female

Age

Criminal History

Presumptive Sentence

Trial

Violent Offense

Drug Offense

Detained Prior to Sentencing

Education

Non-U.S. Citizen

$\begin{array}{cccc}46.411 & 48.298 & 50.561 & 48.014 \\ (62.852) & (70.243) & (66.852) & (70.901)\end{array}$

$\begin{array}{cccc}.254 & .229 & .236 & .225 \\ (.435) & (.420) & (.425) & (.417) \\ .413 & .418 & .421 & .399 \\ (.492) & (.493) & (.494) & (.490) \\ .141 & .134 & .131 & .125 \\ (.348) & (.340) & (.337) & (.331) \\ 34.128 & 34.332 & 34.847 & 34.895 \\ (10.703) & (10.641) & (10.751) & (10.794) \\ 2.359 & 2.482 & 2.498 & 2.472 \\ (1.700) & (1.723) & (1.741) & (1.730) \\ 53.446 & 52.135 & 56.005 & 52.834 \\ (63.190) & (62.033) & (65.069) & (63.801) \\ .039 & .042 & .043 & .034\end{array}$

.039

$(.195)$

.006

$(.079)$

.417

$(.493)$

.601

$(.490)$

.581

$(.493)$

.344

$(.474)$
.042

(.20)

.007

$(.081)$

.362

(.481)

.647

(.478)

.568

(.495)

.366

(.482)
.043

(.203)

.006

(.079)

.357

(.479)

.682

(.466)

.560

(.496)

.377

(.485)
.034

(.181)

.007

(.081)

.328

(.469)

.705

(.456)

.996

(.065)

.416

(.493) 
Table 2. Linear Regression Results for Sentence Length (Pre-PROTECT Era)

\section{Coefficient Standard Quasi- Quasi-}

Error $\underline{\text { Variance }} \underline{\text { Standard }}$

Variables

Young White Men $(\mathrm{n}=19,637)$

$\begin{array}{llll}-.058^{* * *} & .009 & .00005 & .007\end{array}$

Young Black Men $(\mathrm{n}=29,329)$

$.082^{* * * *}$

.008

.00004

.006

Young Hispanic Men $(\mathrm{n}=27,552)$

.009

Young White Women $(n=4,934)$

$-.538^{* * *}$

.009

.00005

.007

Young Black Women $(\mathrm{n}=5,224)$

$-.498^{* * *}$

.015

.00019

.014

$-.346^{* * *}$

.014

.00017

.013

Young Hispanic Women $(n=4,076)$

.017

.00026

.016

White Men, 31-49 $(\mathrm{n}=34,106)$

Black Men, 31-49 $(\mathrm{n}=22,415)$

Hispanic Men, 31-49 $(\mathrm{n}=23,831)$

$-.021^{* * *}$

.00003

.005

$.042^{* * * *}$

.009

.00005

.007

$-.383^{* * * *}$

.009

.00005

.007

$-.419^{* * *}$

.012

.00012

.011

Black Women, 31-49 $(\mathrm{n}=5,102)$

$-.215^{* * * *}$

.014

.00019

.014

$-.033^{* *}$

.017

.00026

.016

Older White Men $(\mathrm{n}=11,854)$

Older Black Men $(\mathrm{n}=2,570)$

Older Hispanic Men $(\mathrm{n}=3,124)$

Older White Women $(\mathrm{n}=1,711)$

$-.125^{* * * *}$

.010

.00008

.009

$-.014$

.020

.00036

.019

$-.354^{* * *}$

.019

.00032

.018

$-.440^{* * * *}$

.024

.00053

.023

$-.303^{* * *}$

.00137

.037

$1.847^{* * * *}$

.034

.00185

.043

Constant

.022

$\mathrm{R}^{2}=.583$

$* * * \mathrm{p}<.001 ; * * \mathrm{p}<.01 ; * \mathrm{p}<.05$

Control Variables Not Shown 
Table 3. Linear Regression Results for Sentence Length (Post-PROTECT Era) Coefficient Standard Quasi-

Variables

Young White Men $(\mathrm{n}=8,135)$

Young Black Men $(\mathrm{n}=10,780)$

$\underline{\text { Error }}$

Variance

$\frac{\text { Standard }}{\text { Error }}$

Young Hispanic Men $(\mathrm{n}=10,303)$

Young White Women $(\mathrm{n}=1,808)$

Young Black Women $(\mathrm{n}=1,668)$

Young Hispanic Women $(\mathrm{n}=1,583)$

White Men, 31-49 $(\mathrm{n}=13,715)$

Black Men, 31-49 $(\mathrm{n}=9,260)$

Hispanic Men, 31-49 $(\mathrm{n}=9,171)$

White Women, 31-49 $(\mathrm{n}=2,938)$

Black Women, 31-49 $(\mathrm{n}=1,878)$

Hispanic Women, 31-49 $(\mathrm{n}=1,369)$

Older White Men $(n=4,596)$

Older Black Men $(\mathrm{n}=1,143)$

Older Hispanic Men $(\mathrm{n}=1,201)$

Older White Women $(n=684)$

Older Black Women $(\mathrm{n}=328)$

Older Hispanic Women $(\mathrm{n}=226)$

$\begin{array}{ccc}-.042^{* *} & .012 & .00010 \\ .054^{* * * *} & .012 & .00008 \\ -.015 & .013 & .00010 \\ -.464^{* * *} & .024 & .00052 \\ -.579^{* * *} & .026 & .00063 \\ -.318^{* * *} & .025 & .00058 \\ - & - & .00006 \\ -.047^{* * *} & .012 & .00010 \\ .023 & .014 & .00012 \\ -.337^{* * *} & .019 & .00032 \\ -.392^{* * *} & .024 & .00052 \\ -.152^{* * *} & .027 & .00068 \\ -.020 & .016 & .00020 \\ -.093^{* *} & .028 & .00073 \\ -.006 & .028 & .00068 \\ -.335^{* * *} & .039 & .00144 \\ -.447^{* * *} & .056 & .00303 \\ -.049 & .063 & .00397 \\ 2.411^{* * *} & .021 & -\end{array}$

.010

.009

.010

.023

.025

.024

.008

.010

.011

.018

.023

.026

.014

.027

.026

.038

.055

Constant

$2.411^{\text {*** }}$

.063

$\mathrm{R}^{2}=.563$

$* * * \mathrm{p}<.001 ; * * \mathrm{p}<.01 ; * \mathrm{p}<.05$

Control Variables Not Shown 
Table 4. Linear Regression Results for Sentence Length (Post-Booker Era) Coefficient Standard QuasiError $\underline{\text { Variance }}$

QuasiStandard $\underline{\text { Error }}$

\section{Variables}

Young White Men $(\mathrm{n}=12,914)$

$-.025^{*}$

Young Black Men $(\mathrm{n}=19,523)$

$.097^{* * *}$

.006

Young Hispanic Men $(\mathrm{n}=18,023)$

Young White Women $(\mathrm{n}=3,171)$

$-.416^{* * * *}$

$-.473^{* * *}$

$-.294^{* * * *}$

Young Hispanic Women $(\mathrm{n}=2,507)$

White Men, 31-49 $(\mathrm{n}=23,534)$

$-$

$-.007$

Black Men, 31-49 $(\mathrm{n}=18,593)$

Hispanic Men, 31-49 $(\mathrm{n}=17,549)$

White Women, 31-49 $(\mathrm{n}=5,043)$

$.083^{* * * *}$

Black Women, 31-49 $(\mathrm{n}=3,263)$

Hispanic Women, 31-49 $(\mathrm{n}=2,512)$

Older White Men $(\mathrm{n}=8,860)$

Older Black Men $(n=2,347)$

Older Hispanic Men $(\mathrm{n}=2,273)$

Older White Women $(\mathrm{n}=1,349)$

Older Black Women $(n=597)$

Older Hispanic Women $(\mathrm{n}=405)$

$-.343^{* * * *}$

$-.340^{* * *}$

$-.150^{* * *}$

.015

$-.085^{* * *}$

.036

$-.284^{* * * *}$

$-.368^{* * *}$

.010

.009

.00006

.008

.00005

.007

.010

.00006

.008

.00029

.017

.020

.00040

.020

.020

.00036

.019

.00004

.006

.00005

.007

.009

.00006

.008

.015

.00020

.014

.018

.00029

.017

.00036

.019

.020

.00010

.010

.00036

.019

.00036

.019

.020

.00073

.027

$-.090$

.00176

.042

.00230

.048

Constant

$2.433^{* * *}$

.048

.020

$\mathrm{R}^{2}=.549$

$* * * \mathrm{p}<.001 ; * * \mathrm{p}<.01 ; * \mathrm{p}<.05$

Control Variables Not Shown 


\begin{tabular}{|c|c|c|c|c|}
\hline & Coefficient & $\frac{\text { Standard }}{\underline{\text { Error }}}$ & $\begin{array}{c}\text { Quasi- } \\
\text { Variance }\end{array}$ & $\frac{\underset{\text { Quasi- }}{\text { Standard }}}{\text { Error }}$ \\
\hline \multicolumn{5}{|l|}{ Variables } \\
\hline Young White Men $(n=3,534)$ & -.013 & .019 & .00023 & .015 \\
\hline Young Black Men $(\mathrm{n}=5,536)$ & $.163^{* * *}$ & .017 & .00014 & .012 \\
\hline Young Hispanic Men $(n=4,675)$ & $.061^{* *}$ & .019 & .00023 & 015 \\
\hline Young White Women $(\mathrm{n}=892)$ & $-.338^{* * *}$ & .034 & .00102 & .032 \\
\hline Young Black Women $(\mathrm{n}=639)$ & $-.300^{* * *}$ & .040 & .00144 & 038 \\
\hline Young Hispanic Women $(\mathrm{n}=703)$ & $-.176^{* * *}$ & 037 & .00123 & .035 \\
\hline White Men, 31-49 $(\mathrm{n}=6,221)$ & - & - & .00012 & 011 \\
\hline Black Men, 31-49 $(\mathrm{n}=5,308)$ & $.068^{* * * *}$ & .017 & .00017 & .013 \\
\hline Hispanic Men, 31-49 $(\mathrm{n}=4,691)$ & $.131^{* * *}$ & .019 & .00023 & 015 \\
\hline White Women, 31-49 $(\mathrm{n}=1,357)$ & $-.281^{* * * *}$ & .028 & .00068 & .026 \\
\hline Black Women, 31-49 $(\mathrm{n}=785)$ & $-.284^{* * *}$ & .037 & .00123 & 035 \\
\hline Hispanic Women, 31-49 $(\mathrm{n}=648)$ & $-.075^{*}$ & .038 & .00130 & 036 \\
\hline Older White Men $(\mathrm{n}=2,529)$ & 027 & .021 & .00036 & 019 \\
\hline Older Black Men $(n=659)$ & -.044 & .037 & .00123 & .035 \\
\hline Older Hispanic Men $(\mathrm{n}=663)$ & $.082^{*}$ & .037 & .00123 & .035 \\
\hline Older White Women $(n=404)$ & $-.300^{* * *}$ & .051 & .00250 & .050 \\
\hline Older Black Women $(\mathrm{n}=155)$ & $-.210^{*}$ & .085 & .00706 & 084 \\
\hline Older Hispanic Women $(\mathrm{n}=132)$ & -.034 & 081 & .00640 & 080 \\
\hline Constant & $2.380^{* * *}$ & .095 & & - \\
\hline
\end{tabular}

$\mathrm{R}^{2}=.549$

$* * * \mathrm{p}<.001 ; * * \mathrm{p}<.01 ; * \mathrm{p}<.05$

Control Variables Not Shown 